
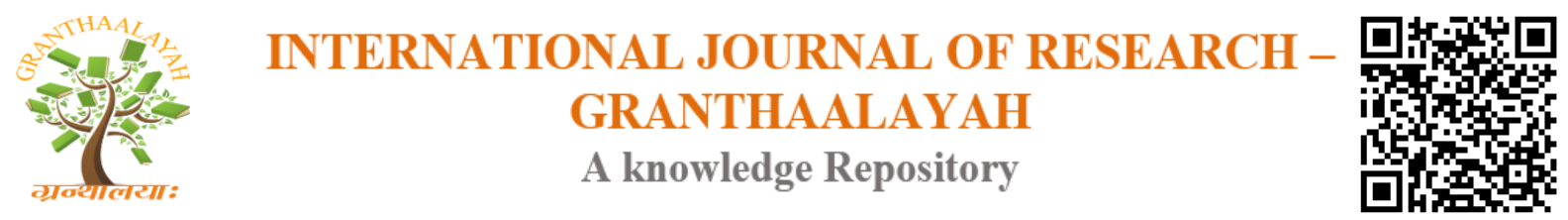

Science

\title{
SIMULATION OF HIGHER EDUCATIONAL ESTABLISHMENT COMPETITIVENESS
}

\author{
Alexander S. Ryzhkov ${ }^{* 1}$, Konstantyn V. Koshkin², Natalia R. Knyrik², Rostyslav S. \\ Ryzhkov $^{3}$ \\ ${ }^{* 1}$ Educatinal Scientific Center of International Cooperation, Admiral Makarov National \\ University of Shipbuilding, Mykolaiv, Ukraine \\ ${ }^{2}$ Educatinal Scientific Institute of Computer Sciences and Technologies, Admiral Makarov \\ National University of Shipbuilding, Mykolaiv, Ukraine \\ ${ }^{3}$ Educatinal Scientific Center of European Integration, Admiral Makarov National University of \\ Shipbuilding, Mykolaiv, Ukraine
}

\begin{abstract}
The success of International Joint Educational Programs of the Educational Establishments based on effective management. This makes a need for predicting the competitiveness indicators in order to analyze different strategies for the expansion of higher education establishments and the picking up the best scenarios of its market play. The simulation methodology makes possible to performe analysis management that contains elements of actions that influenced by random factors. Using the method of system dynamics as the main tool is due to the complexity of the strategic alternatives selection in a dynamically developing situation, under conditions of external and internal uncertainty. The initial state of performed simulation was based on the parameters that define the market share and the number of potential students of the joint educational program between Admiral Makarov National University of Shipbuilding and partner in Zhejiang City, China. Sensitivity analysis experiments allow determining the influence of the initial hypotheses and the key parameters values on the model output parameters of the interference of competitiveness factors under uncertainty conditions. This significantly improves the effectiveness of management processes.
\end{abstract}

Keywords: Project Management; Promotion; Education System; Effectiveness-Performance; International Experience; Knowledge Management; Simulation; Managerial Cognition; Education Systems.

Cite This Article: Alexander S. Ryzhkov, Konstantyn V. Koshkin, Natalia R. Knyrik, and Rostyslav S. Ryzhkov. (2017). "SIMULATION OF HIGHER EDUCATIONAL ESTABLISHMENT COMPETITIVENESS." International Journal of Research Granthaalayah, 5(8), 26-35. https://doi.org/10.29121/granthaalayah.v5.i8.2017.2179. 


\section{Introduction}

The problem of increasing competitiveness is one of the primary tasks for optimizing the management of higher education institutions, working in conditions of the market and crisis. Optimization of university exchange relations with competing organizations is the main task of effective management. This leads to the need for simulation and predicting the dynamics of competitiveness indicators in order to analyze alternative strategies for the development of higher education institutions and the selection of optimal scenarios of its market conduct. The concept of competitiveness is still not clearly defined by experts, and depends on the subject area: enterprise, educational institution, group of companies, industry, region, sector, etc. There are also a number of unresolved problems: absence of universal mathematical models for competitiveness assessing and forecasting, a weak hidden regularities account of the competition process in existing models, complexity of automation and inadequate decision speed, lack of specialized competitiveness management software and tools in the market. Simulation modeling allows predicting the dynamics of competitiveness and making decisions on the selection of measures for their increase (Koshkin, Knyrik, \& Voznyy, 2016).

University management competitiveness requires the adoption of wise and scientifically based managerial decisions. It is necessary to take into account a lot of factors that have a significant impact on the management process, the quality of decisions and results. The decision-maker can use different methods in the developing process and making managerial decisions: information search, data mining, databases values search, reasoning based on precedents, simulation modeling, evolutionary computation and genetic algorithms, neural networks, situation analysis, collective modeling, artificial intelligence techniques (Logunova, 2012). The genetic algorithm realizes a random search method, based on natural selection - the main mechanism of evolution, allowing finding problems solutions that are close to optimal (Rutkovskaya, Pipinskiy, \& Rytkovskiy, 2008).

The basis of the decision-making process during the use of the simulation method is the model of the research object that can be a complex of interrelated simulation and optimization models with a multitude of dynamic and information links between all levels models (Lychkina). Expert details the problem and model, generates alternatives, formulation of a directed computational experiment on the simulation model and selection and ranking criteria. Simulation modeling technology allows taking into account the expert subjective preferences and his experience in the decision-making process.

Semistructured are systems that are characterized by a multidimensional nature of the occurring processes in them and their interconnectedness, the lack of sufficient quantitative information about the dynamics of processes, as well as the processes nature variability in time.

Cognitive modeling tools are used to study weakly semistructured systems. Information about the system in the cognitive model is represented in the form of a set of concepts and the causalinvestigatory network (cognitive map) linking them. It reflects the expert's subjective representation on the laws and patterns that are inherent in the modeled system. Analytical methods focused on the research of the system structure and obtaining predictions of its behavior 
during various control actions are applied to the cognitive map with the purpose of effective management strategies synthesis (Avdeev, Kovriga, \& Makarenko, 2007).

The solution search based on precedents is to determine the similarity measure of the current situation to precedent situations from the rule database (RD). The parameters weights specified by the expert for the situation from the RD are taken into account in this case. The similarity measure depends on the closeness of the current situation to the precedent situation (Varshavskiy, 2008).

The neural network device (Borisov, Kruglov, \& Fedulov, 2007) is simple to use and allows reproducing complex dependencies. It is used to solve problems of forecasting, classification or management.

The choice of method depends on the set of tasks that need to be resolved to make effective management decisions.

The purpose of the study is to increase the effectiveness of taken decisions to improve the competitiveness of the university on the basis of simulation modeling.

\section{Materials and Methods}

The simulation methodology allows performing effective analysis and structure management that simultaneously contains elements of continuous and discrete action and is influenced by numerous random factors. It is described by cumbersome relationships (Hamilton, 2004). Various combinations of the principles of imitation (Lychkina N. , 2005), cognitive modeling (Bai, et al., 2013), and Petri nets (Kotov, 1984) are used in the development of models. Using the method of system dynamics as the main tool is due to the complexity of the strategic alternatives selection in a dynamically developing situation, under conditions of external and internal uncertainty (Lychkina N. N., 2007).

The use of different modeling methods by the decision maker enables:

- Use multi-criteria in the model development and study;

- Conduct a comprehensive analysis of a large number of alternatives and choose an option that matches the selected criteria;

- Explore dynamic situations, when the system and environment parameters change in the implementing projects process;

- To study the influence of structural organization features and feedback loops on the behavior;

- Interpret system flow diagrams. This makes it possible to make concerted decisions;

- Use simulation models as a tool for conducting a large number of experiments of a "what-if" set;

- To conduct scenario research on simulation models.

\section{Results and Discussions}

AnyLogic system (AnyLogic) is used for developing the model of mutual influence of university competitiveness factors (Fig. 1). 
The initial state of the simulated system is determined by the parameters values that define the market share and the number of potential students of the Admiral Makarov National University of Shipbuilding in Zhejiang, China (Table 1).

Table 1: Initial state of the simulated system

\begin{tabular}{|l|l|}
\hline Model parameter & Initial value \\
\hline Capacity of the market segment & 1000 per. \\
\hline Market share & $0.1 \%$ \\
\hline The number of potential students & 100 per. \\
\hline Training cost & $2500 \mathrm{RMB} / \mathrm{year}$ \\
\hline Quality & 0.5 point \\
\hline University rating & 0.6 point \\
\hline Teacher rating & 0.3 point \\
\hline Teacher qualifications & 0.5 point \\
\hline Group size & 15 per. \\
\hline Student progress & 0.2 point \\
\hline Evaluation of teachers & 0.2 point \\
\hline
\end{tabular}

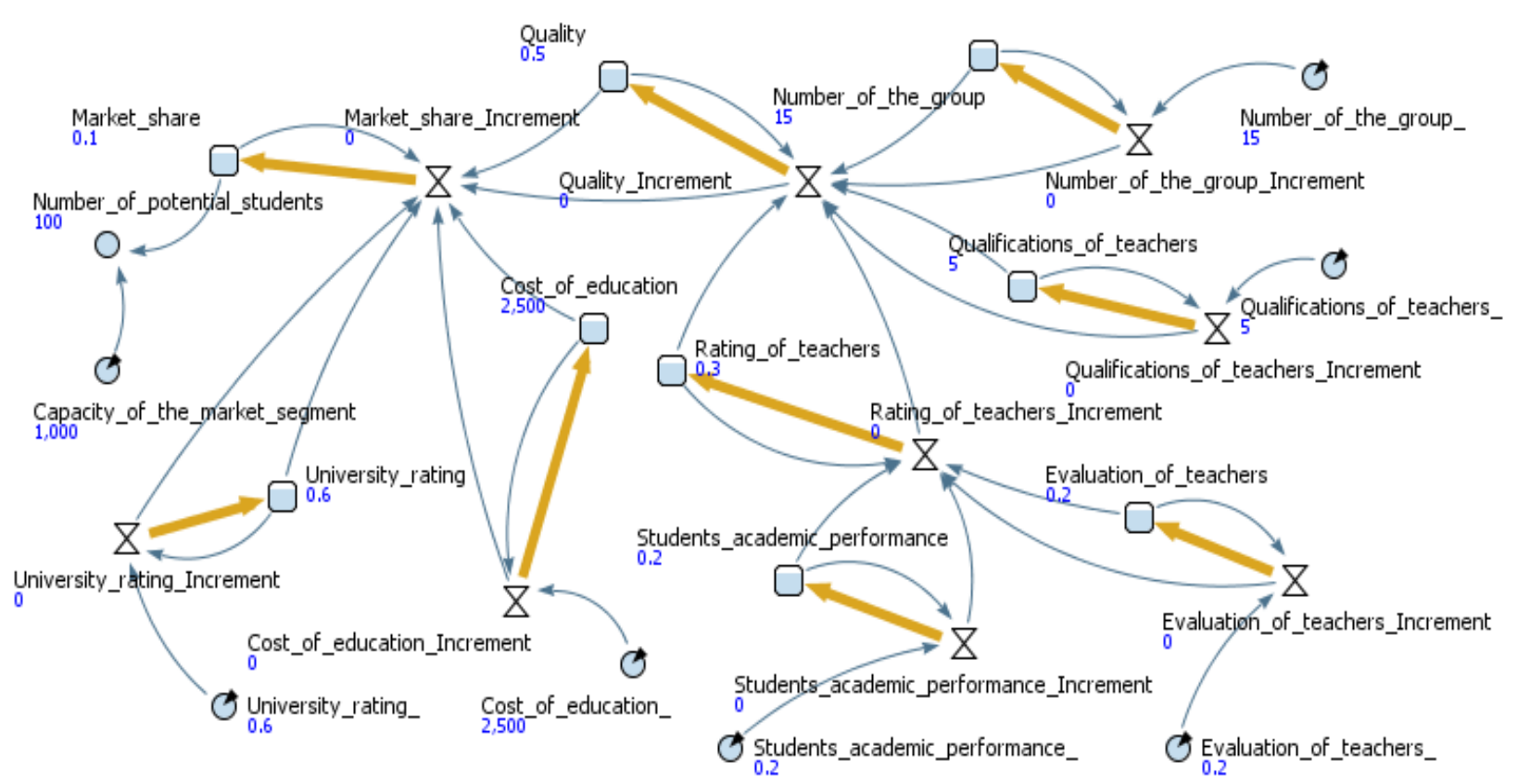

Figure 1: The model the impact of competitive factors on the university market share.

Parameters that define their target (necessary) values are determined for input variables for scenario analysis. In our case, they are:

«Training_cost_»,

«Group_size_»,

«University_rating_»,

«Teacher_qualifications_»,

«Student_progress_»,

«Evaluation_of_teachers_». 
It is possible to analyze the consequences of possible design solutions by changing these parameters in the simple experiment mode.

Thus, for example, the number of potential NUS students at given parameters is 100 persons (market share $-0,1 \%$, market segment capacity - 1000 persons).

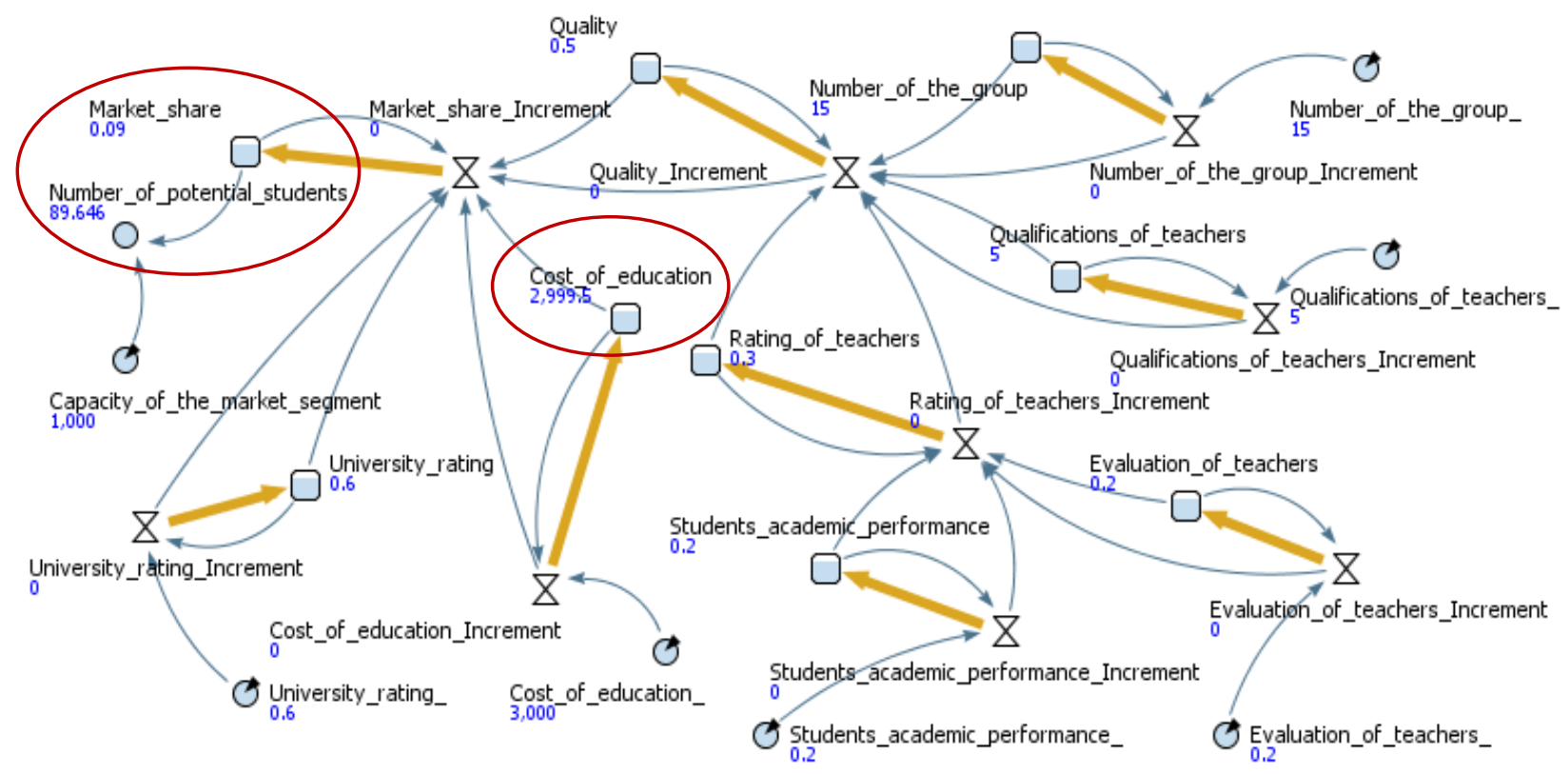

Figure 2: The model parameters with an increase in training cost by $20 \%$

If it is necessary to increase the training cost by 20\% (3 $000 \mathrm{RMB} / \mathrm{year}$ ) under the influence of objective factors, then the competitiveness of the university will decrease: the market share will decrease to $0,09 \%$ and the number of potential students in Zhejiang will be about 90 people (Fig. 2).

Fig. 3 shows that it is possible to compensate for the consequences after increasing the value of the " Training_cost_" in the model and returning to the original market share value $=0,1 \%$ by improving the quality of training by attracting more qualified teachers. The parameter "Teacher_qualification_" is a normalized value, estimated in points in the range [1; 10]. Academic degree, academic rank, work pedagogical seniority of teachers is taken into account while determining of this parameter value. 


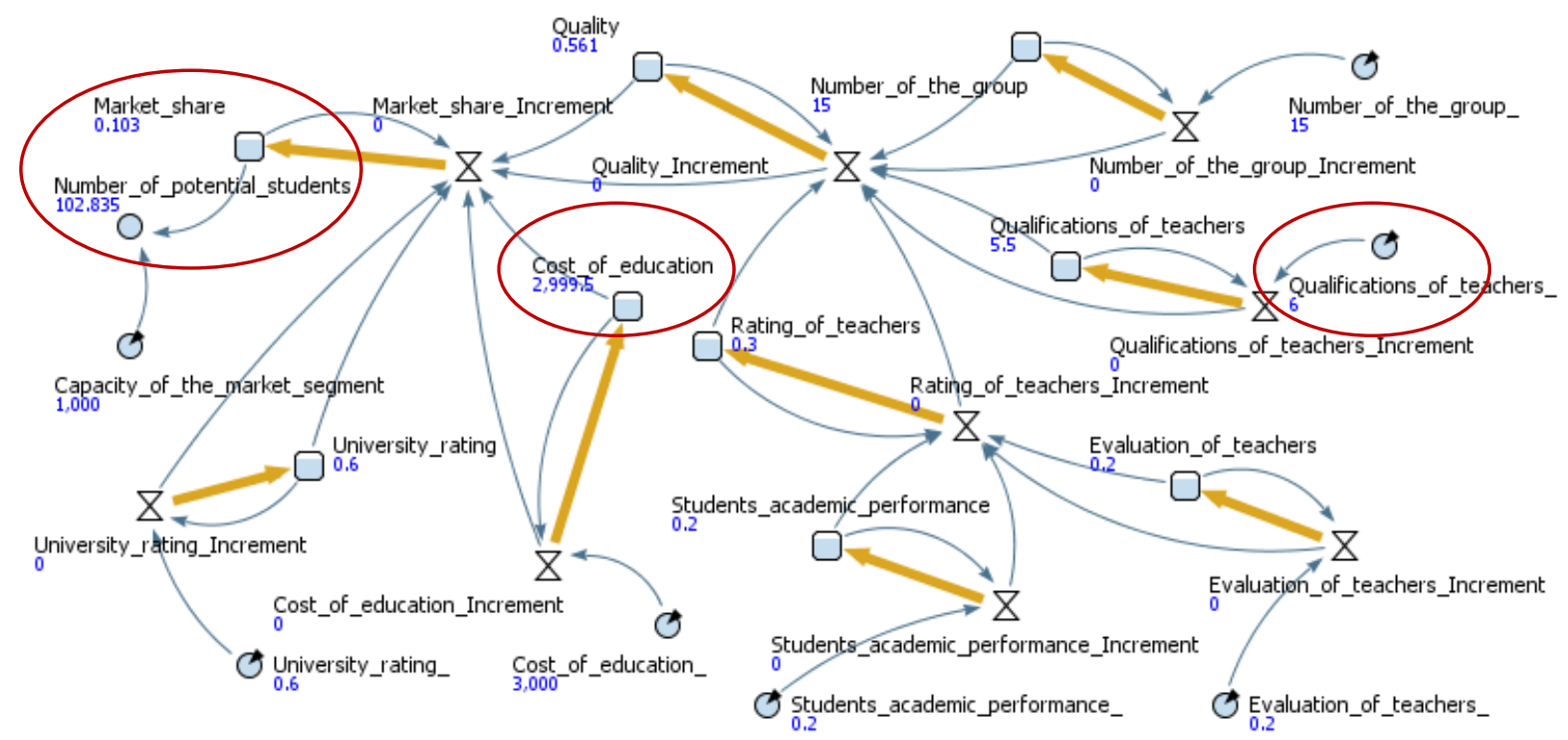

Figure 3: Compensation of the increasing training cost by professional teacher advancement

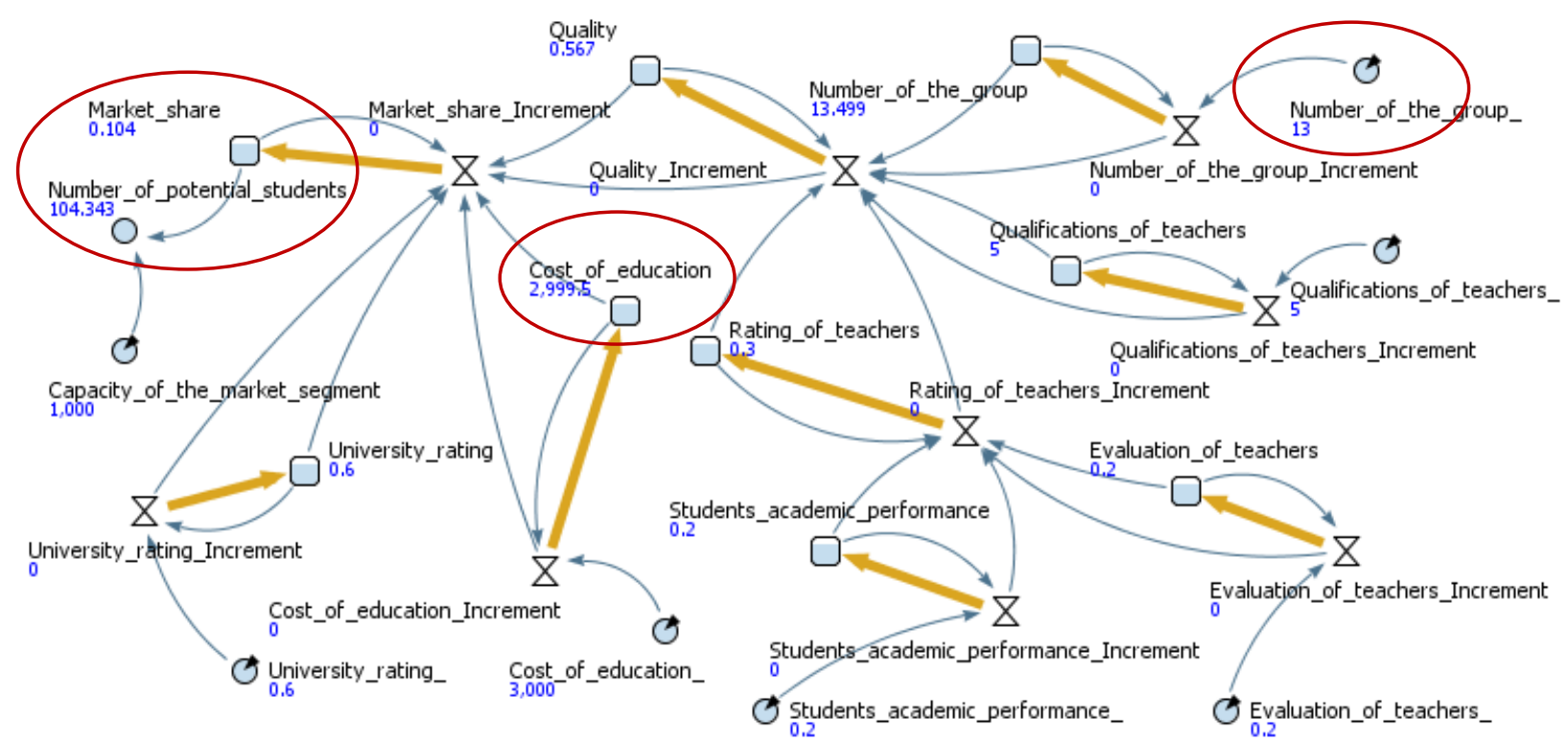

Figure 4: Compensation of the increased training cost by reducing a group size

Fig. 4 presents an alternative solution - to improve the quality of education by reducing the number of students in the group.

The university has the opportunity to reduce the training cost, without losing its market position with an increase in the training quality, for example, if the student's progress has improved and, as a consequence, the teachers rating improved also (Ryzhkov, 2017). The mutuality of the competitiveness factors can be seen by conducting a corresponding scenario experiment with the simulation model. 
Sensitivity analysis experiments help to evaluate the sensitivity of simulation results from specific model parameters. There are several "runs" of the model when changing the value of one of the parameters. Then it is shown how the simulation results are affected by these changes.

The experiment with the parameters variation and the model's reaction analysis helps to assess how sensitive the model forecast is to the hypothesis change that underlies the model. The change in factor values separately is recommended during the sensitivity analysis. This allows ranking their impact on the resulting metrics.

The sensitivity research allows determining the strategy for planning experiments on the simulation model (Lychkina N. , 2005). If the model is insensitive for any component of the model's parameters vector $x_{i}, i=\overline{1, n}$, then it is not included in the plan of the simulation experiment. Saving the simulation time resource is achieved during this. The values of the parameters vary systematically within certain limits $(\underline{x}, \bar{x})$ and the influence of these variations on the system characteristics is observed. If the results change very strongly with insignificant changes in the some parameters values, then it is necessary to conduct additional studies in order to obtain more accurate estimates. Conversely, if the final results do not change during the change in the parameter values within wide limits, further experimentation in this direction is unjustified.

The influence of key indicators on the output parameters vector can be analyzed during the experiments of interference model sensitivity analyzing of competitiveness factors to all input parameters.

The graphs in Fig. 5 illustrate the sensitivity of the number of potential student's indicator to the change in the parameters "Training_cost_" and "University_rating _".

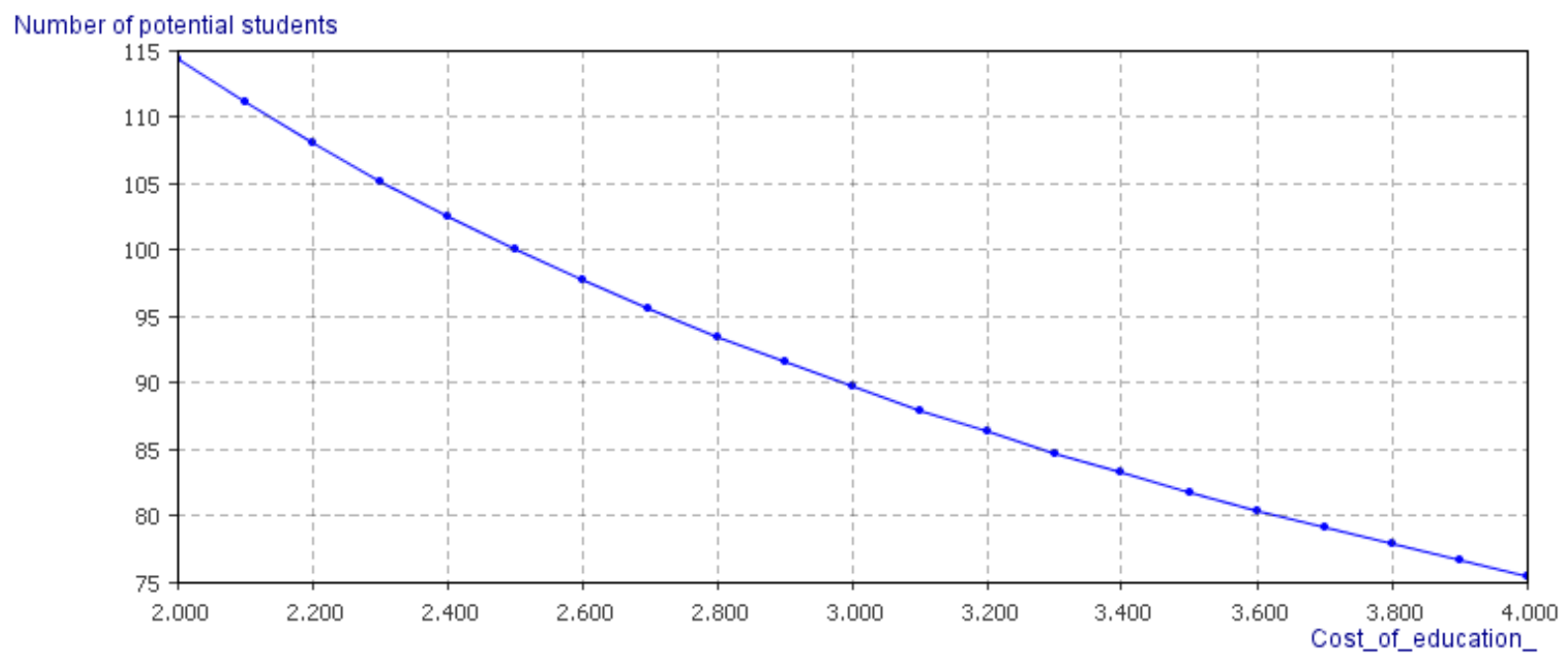

a 


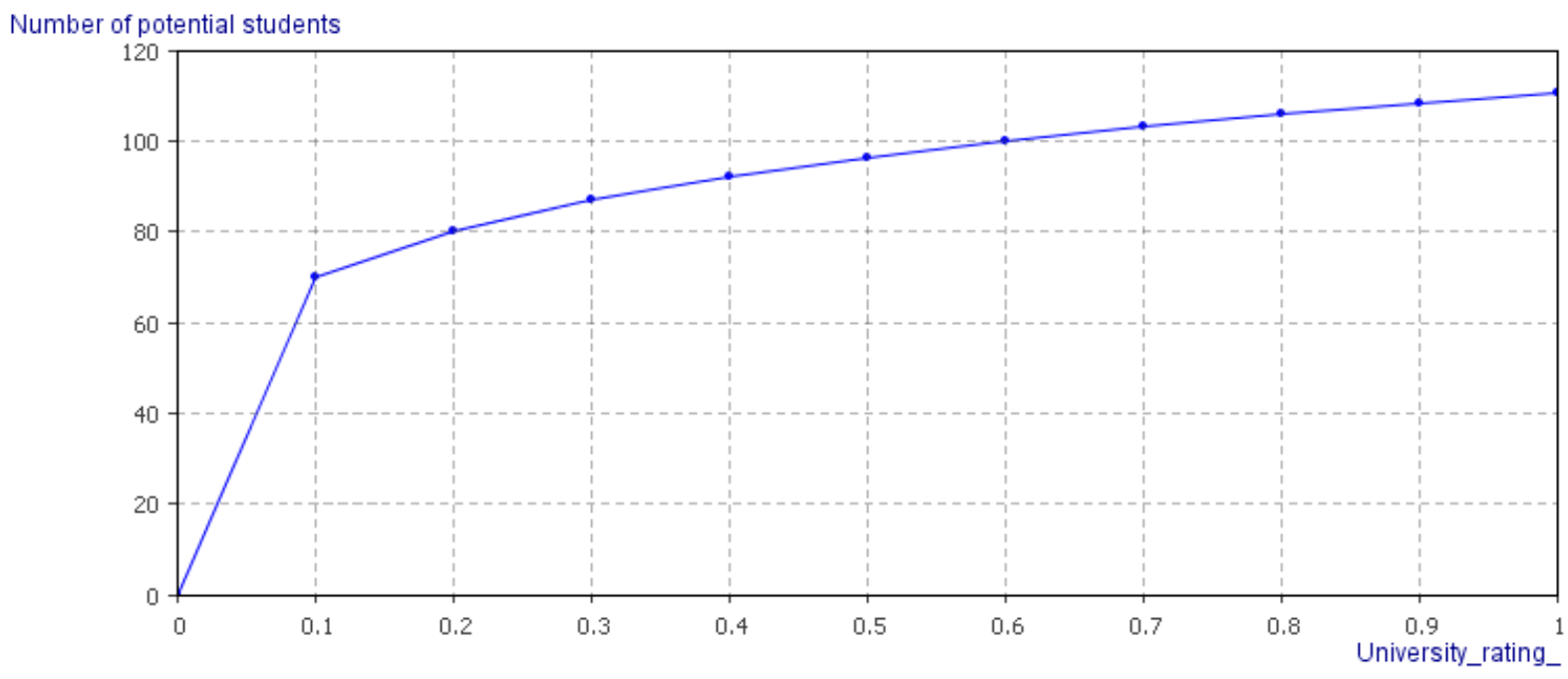

6

Figure 5: Sensitivity analysis of the number of potential students to changing parameters: a Training_cost_; - University_rating _

Sensitivity analysis will also make adjustments to the developed models (simplified). For example, migrate from the distribution law to the mean variable value usage and some subsystems discarded generally (or not itemize the processes). Conversely, sensitivity analysis can show model parts that would be useful to develop in more detail.

We introduce the following notation for the model elements for the sensitivity estimation: $X=\left\{x_{1}, x_{2}, \ldots, x_{n}\right\}$-input data vector, $Y=\left\{y_{1}, y_{2}, \ldots, y_{m}\right\}$ - output vector. Change interval $\left(\underline{x_{i}}, \overline{x_{i}}\right)$ is determined for each input parameter $x_{i}, i=\overline{1, n}, \underline{x_{i}}$ - bottom limit value, $\overline{x_{i}}$ - top limit value. The remaining vector $\mathrm{X}$ components do not change. Model experiments will be conducted and for the pair $\left(x_{i}, \overline{x_{i}}\right)$ we get the model response vector $\left\{\left(\underline{y_{j}^{i}}, \overline{y_{j}^{i}}\right)\right\}, j=\overline{1, m}$, where $\underline{y_{j}^{i}}=A\left(\underline{x_{i}}\right), \overline{y_{j}^{i}}=A\left(\overline{x_{i}}\right), j=\overline{1, m}, \mathrm{~A}$ - an operator that represents multiple input parameters to a set of output parameters. Absolute and relative values can be used to estimate sensitivity. Calculate the increments parameters vector in the latter case:

$\Delta x_{i}=\frac{\left(\overline{x_{i}}-\underline{x_{i}}\right)^{2}}{\left(\overline{x_{i}}+\underline{x_{i}}\right)} \cdot 100 \%, i=\overline{1, n}$.

Each increment input parameter $\Delta x_{i}, i=\overline{1, n}$ will match the output vector increments factors: 
$\Delta y_{j}^{i}=\frac{\left(\overline{y_{j}^{i}}-\underline{y_{j}^{i}}\right)^{2}}{\left(\overline{y_{j}^{i}}+\underline{y_{j}^{i}}\right)} \cdot 100 \%, j=\overline{1, m}$.

Model sensitivity on $\mathrm{i}$-th component of the input parameters vector $\mathrm{X}$ is determined by a pair of values $\left(\Delta x_{i}, \Delta y^{i}\right)$, where $\Delta y^{i}=\max _{j=1}^{m}\left\{\Delta y_{j}^{i}\right\}$.

The sensitivity of the simulation model is represented by the value of the minimum increment of the selected quality criterion. It is calculated from statistics modeling with a consistent variation of the modeling parameters over the entire range of their variation.

\section{Conclusions \& Recommendations}

A series of experiments with an imitation model of the mutual influence of competitiveness factors was leaded. Factors implement various scenarios of design solutions aimed at the key indicators values of the university position in the educational services market.

Sensitivity analysis experiments allow determining the influence of the initial hypotheses and the key parameters values on the model output parameters of the interference of competitiveness factors under uncertainty conditions. This significantly improves the effectiveness of management processes.

\section{References}

[1] AnyLogic. (б.д.). Multi-approach simulation simulation. Получено из AnyLogic: http://www.anylogic.ru/.

[2] Avdeev, Z., Kovriga, S., \& Makarenko, D. (2007). Cognitive modeling and solving the problems of managing weakly structured systems (situations). Moscow: ИПУ РАН.

[3] Bai, S., Blintsov, V., Bushuev, D., Voznyy, A., Gayda, A., Zaporozhets, I., и др. (2013). The management of the organization of the organization of the organization of the sea and sea complex. Mykolaiv: Torubara Publishing.

[4] Borisov, V., Kruglov, V., \& Fedulov, A. (2007). Fuzzy models and networks. Moscow: Goriachaya Linia - Telecom.

[5] Hamilton, J. D. (2004). Time Series Analysis. New Jersey: Princeton University Press .

[6] Koshkin, K., Knyrik, N., \& Voznyy, A. (2016). Decision-making in the implementation of IT projects based on simulation. Journal of NTU "HPI" , 12-16.

[7] Kotov, V. E. (1984). Petri nets. Moscow: Nauka.

[8] Logunova, E. (2012). hysics and mathematics and information technologies: problems and development trends. MATHEMATICAL MODELS OF DECISION SUPPORT SYSTEMS. IV. Novosibirsk: СибАК.

[9] Lychkina, N. (б.д.). Modern technologies of simulation and their application in information business systems and decision support systems . http://itclaim.ru/Library/Books/SC/articles/sovremennye_tehnologii_immitacionnogo/sovremennye_tehn ologii_immitacionnogo.html .

[10] Lychkina, N. N. (2007). Simulation models in procedures and systems for supporting strategic decision-making for enterprises (T. 1). Business-Informatics.

[11] Lychkina, N. (2005). Simulation of economic processes. Moscow: Akademiya IT. 
[12] Rutkovskaya, D., Pipinskiy, M., \& Rytkovskiy, P. (2008). Neural networks, genetic algorithms and fuzzy systems. Moscow: Gorachaya Linia - Telecom.

[13] Ryzhkov, A. (2017). Assessment of the quality of teaching as an element of the management of a joint international educational project. Science Rise , 3, 51-59.

[14] Varshavskiy, P. (2008). 1th National Conference KII-2008. Mechanisms of plausible reasoning on the basis of precedents (accumulated experience) for expert diagnosis systems. 2, стр. 321329. Moscow: Lenand.

*Corresponding author.

E-mail address: oleksandr.ryzhkov@ nuos.edu.ua 